\title{
Role of minimally invasive percutaneous fixation in thoracolumbar fractures: a prospective study
}

\author{
Sherief Ahmed Elenany, Hazem Adel Alkosha and Mohamed Safwat Ibrahiem
}

\begin{abstract}
Background: Each year, there are approximately 5 million new vertebral fractures worldwide. Being a mobile flexible segment that is prone to severe stresses and loads, thoracolumbar fractures are considered one of the most controversial and challenging fracture types to manage.

Objective: The aim of this study is to explore the technique and to evaluate feasibility, safety, and outcome of percutaneous transpedicular fixation in the management of thoracolumbar fractures.

Methods: This study was carried out in the period between May 2016 and June 2017, where 20 consecutive patients with thoracolumbar fractures, based on TLICS scoring and neurological status, underwent a posterior percutaneous transpedicular fixation. The mean age was 33.85 years, range 20-49years. Patients were followed up for 12 months. Patients had their clinical outcomes reviewed and evaluated in terms of cosmesis by visual analog scale (VAS) and in terms of Cobb angle correction.

Results: The length of the procedure varied from 120 to $180 \mathrm{~min}$ with mean time of $154.50 \mathrm{~min}$. There was no significant blood loss in all cases. The volume of blood loss ranged from 150 to $200 \mathrm{cc}$ with mean loss of $174.25 \mathrm{cc}$.

No major intraoperative complications happened in our study cases. Six cases had only one laterally malpositioned screw each. All cases returned to their previous activity without limitations (E5). Those who were completely pain free (F5) were 15 patients. Only five patients were suffering from moderate pain (F4). The Prolo scale was either 9 or 10 with mean of 9.60 .

Conclusion: By comparing our results with other studies, we found more or less equivalence in terms of neurological recovery, functional outcome, fusion rate, and maintenance of correction gain. However, the cosmesis scores for patients in the study were great.
\end{abstract}

Keywords: Minimally invasive, Thoracolumbar fractures, Percutaneous, Transpedicular screws

\section{Introduction}

Although spine fractures represent only a minority in all trauma patients, their influence on the patients, social and financial environment is more significant than other injuries [1].

In the last 20 years, interest in spine fractures grew because new and advanced surgical treatment options were established. A large number of publications, describing various surgical techniques for the reduction and

\footnotetext{
* Correspondence: dr.sherief89ahmed@gmail.com;

sherief.elenany@suezuni.edu.eg

Faculty of Medicine, Mansoura University, Mansoura, Egypt
}

fixation of thoracolumbar fractures, followed by discussions among the authors has not led to a general consensus on the optimal treatment [2].

Pedicle screw instrumentation enables a rigid construct to promote stability and fusion for numerous spinal pathologies including trauma, tumors, deformity, and degenerative disease [3].

Conventional open spine surgery has several reported limitations including extensive blood loss, postoperative muscle pain, and infection risk. The paraspinal muscle dissection involved in open spine surgery can cause muscular denervation, increased intramuscular pressure, 
ischemia, necrosis, and revascularization injury resulting in muscle atrophy and scarring, often associated with prolonged postoperative pain and disability [4].

Recently, minimally invasive percutaneous transpedicular screw fixation has been developed and showed a significant role in minimizing approach-related morbidity [5].

Minimally invasive techniques in spinal surgery are increasing in popularity due to numerous potential advantages, including reduced length of hospital stay, blood loss, and requirements for postoperative analgesia as well as earlier return to work [6].

However, some disadvantages and complications of percutaneous transpedicular systems with conventional pedicular screw applications were reported as misplaced screws, nerve root injury, spinal cord injury, pedicular fracture, and CSF fistula [7].

\section{Materials and methods}

This was a case series carried on prospectively in the Neurosurgery Department, Mansoura University, by operating on 20 cases admitted to the Emergency Hospital with the diagnosis of thoracolumbar fractures. The cases were operated in the Mansoura Emergency Hospital by a neurosurgical team. The study started in May 2016, and the operated cases were followed up to 12 months. Twenty cases of thoracolumbar fractures underwent percutaneous transpedicular fixations.

\section{Ethical consideration}

The protocol was submitted for approval by the local Institutional Research Board (IRB), Faculty of Medicine, Mansoura University, with a code number (MS/16.04.76). Informed written consent was obtained from all subjects in the study after insuring confidentiality.

\section{Patients}

Our study included patients with thoracolumbar spine fractures that needed surgical stabilization via posterior fixation (fractures affecting T10 to L2). The inclusion criteria of study eligibility include as follows: age between 18 and 60 years, trauma fracture of thoracic and/ or lumbar spine needing dorsal instrumentation with no significant anterior column damage requiring anterior reconstruction, i.e., any thoracolumbar injury classification and severity (TLICS) score, and the load-sharing score was less than or equal to 6 provided that there was no neurological deficit (Tables 1 and 2), while the exclusion criteria include as follows: neurological deficit mandating decompression of neural elements, retropulsed segment occupying more than $50 \%$ of spinal canal, previous spine surgery at the same level, osteoporosis, coagulopathy not corrected at time of surgery, significant posttraumatic segmental kyphosis more than or equal to $10^{\circ}$, and fracture dislocation of the thoracolumbar spine.
Table 1 TLICS score [8]

\begin{tabular}{ll}
\hline Parameter & Points \\
\hline Morphology & 1 \\
Compression fracture & 2 \\
Burst fracture & 3 \\
Translational/rotational & 4 \\
Distraction & \\
Neurologic involvement & 0 \\
Intact & 2 \\
Nerve root & \\
Cord, conus medullaris & 3 \\
$\quad$ Incomplete & 2 \\
$\quad$ Complete & 3 \\
Cauda equina & 3 \\
Posterior ligamentous complex & \\
Intact & \\
Injury suspected/indeterminate & 0 \\
Injured & 2 \\
Management & 3 \\
Non-operative & \\
Non-operative or operative & \\
Operative & -3 \\
\hline
\end{tabular}

\section{Surgical procedure}

Prior to the procedure, an informed consent is taken from all patients. Following general anesthesia, the patient is placed in a prone position on a lumbar frame. Under lateral fluoroscopic imaging obtained by fluoroscopic C-arm, the correct level is identified using a guidewire localizer.

\section{Operative technique}

System tools

A DepuySpine Viper 2 system was used with these tools (Fig. 1): guidewire, tap cannula, self-drilling cannulated tap, dilators, cannulated polyaxial viper screws with extensions, rods, measurements, and rod holder.

A guidewire was placed on the back of the patient perpendicular to the axis of the spine at the targeted level. Using A-P fluoroscopy, the guidewire was adjusted to transect the center of both pedicles in the cephaladcaudal direction. A surgical marker was used to transfer

Table 2 Load-sharing classification [9]

\begin{tabular}{llll}
\hline Score & 1 point & 2 points & 3 points \\
\hline Sagittal collapse & Mild $(<30 \%)$ & Moderate $(30-60 \%)$ & Sever $(>60 \%)$ \\
Fragment shift & Mild $(1 \mathrm{~mm})$ & Moderate $(2 \mathrm{~mm})$ & Sever $(>2 \mathrm{~mm})$ \\
Kyphosis correction & Mild $\left(<3^{\circ}\right)$ & Moderate $\left(3-9^{\circ}\right)$ & Sever $\left(\geq 10^{\circ}\right)$ \\
Total & 3 & 6 & 9 \\
\hline
\end{tabular}




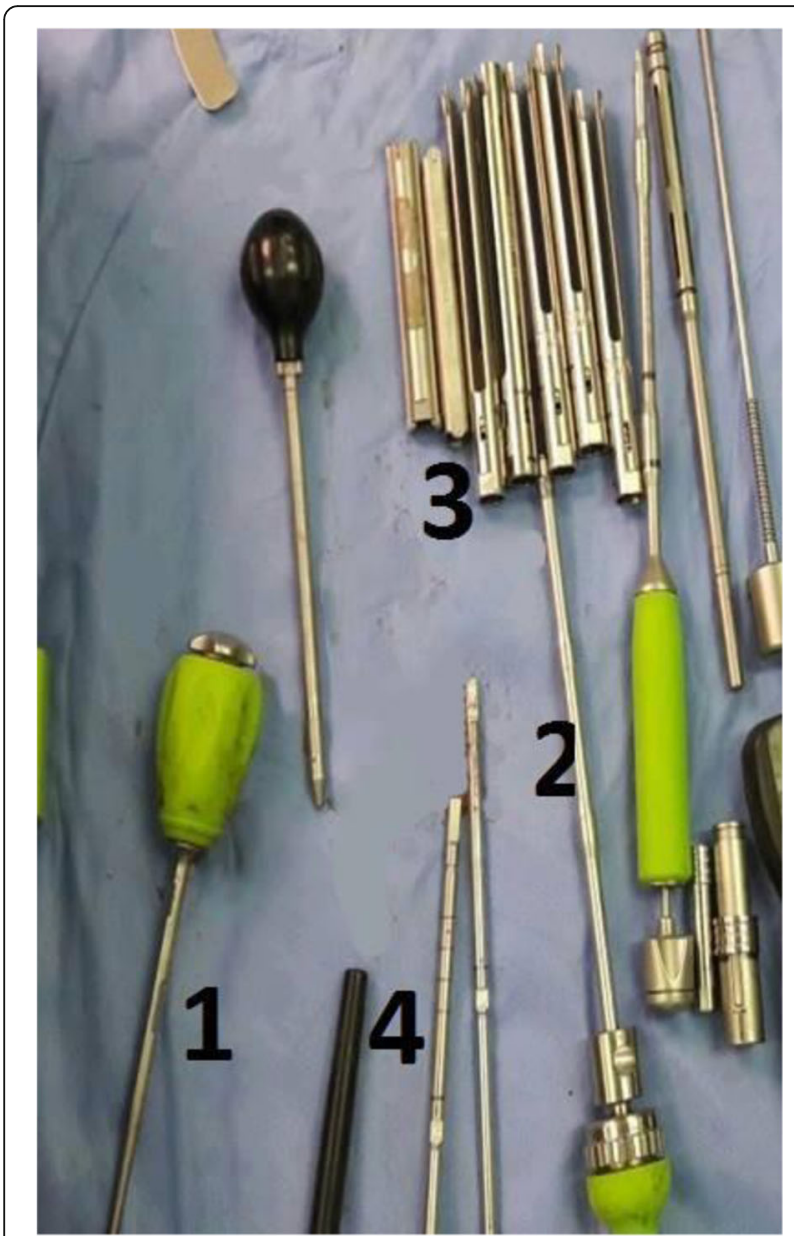

Fig. 1 Tools used: the most important 1. Tap cannula. 2. Self-drilling cannulated tap. 3. Cannulated polyaxial extensions. 4. Dilators

that plane to the patient's back (Fig. 2). Guidewires were placed on the patient parallel to the axis of the spine. Using A-P fluoroscopy, the position of the guidewire was adjusted to align to the lateral pedicle wall of the targeted level and the adjacent levels. The lateral pedicle wall of adjacent levels could also be estimated at this time. A surgical marker was used to transfer this plane onto the patient (Fig. 3). The skin incision for each level should be at least $1 \mathrm{~cm}$ lateral to the intersection of the two lines (Fig. 4). After making a skin incision, the fascia was incised using the tip of the blade with a scalpel to facilitate passing of the tap cannula. The tap cannula was then introduced through the skin incision in slight medial trajectory until a bony structure was felt. Using fluoroscopy, the tip of the tap cannula was checked and adjusted at a 9 o'clock position in left pedicles and at a 3 o'clock position in right pedicles. Pedicles were tapped with the tap cannula from the lateral pedicular margin until it reached the medial margin of the pedicle in AP view. At this stage, the position of the tip was confirmed on lateral view to have crossed the pedicle-body junction

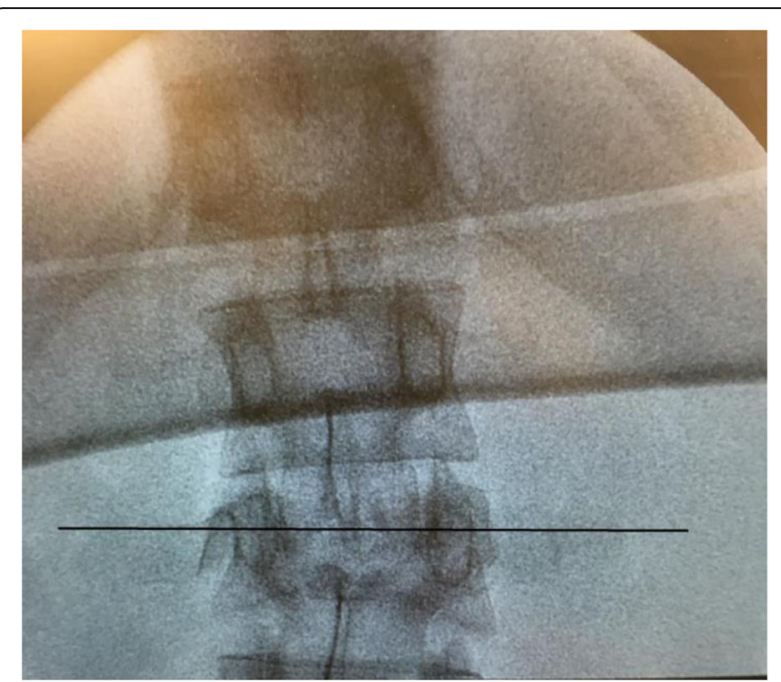

Fig. 2 A guidewire placed on the back of the patient perpendicular to the axis of the spine

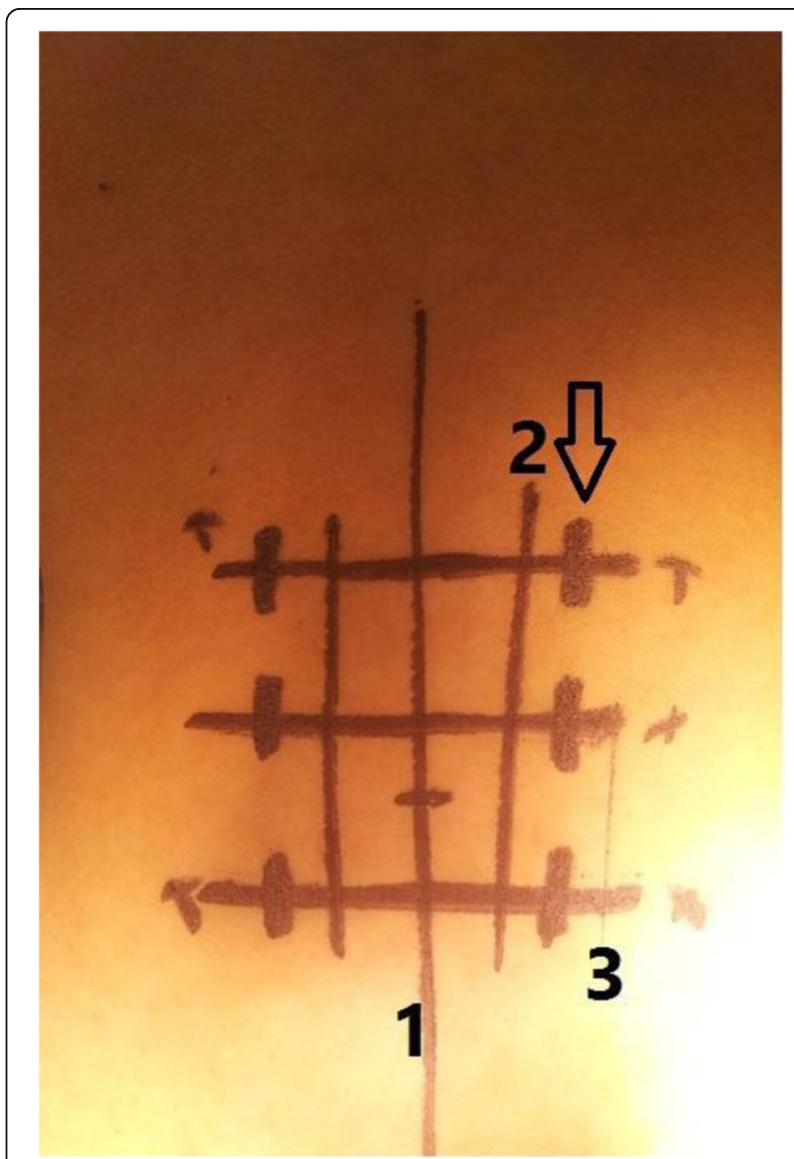

Fig. 3 1. Midline of the back. 2. Line drawn targeting lateral margins of the pedicles. 3. Arrow indicating the incision site $1 \mathrm{~cm}$ lateral to the lateral margin of the pedicles 


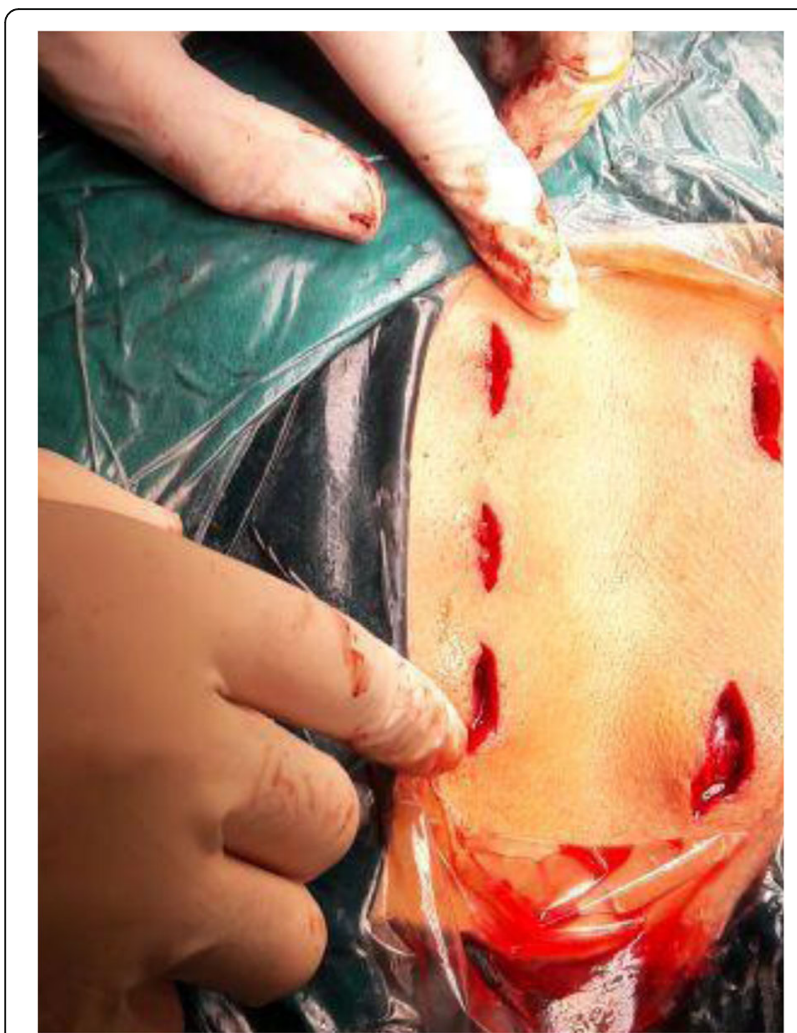

Fig. 4 Skin incisions in a patient planned to undergo percutaneous fixation one level above and one level below with injured level screw on the left side; the right pedicle of the involved level was damaged

(Fig. 5). The 7-mm dilator was inserted into the cannula and was rotated with pressuring downward until the two pieces "snapped" and locked with each other. The joined instrument was advanced along the guidewire until the distal tip of the instrument touched the pedicle which was confirmed with radiograph. The cannula is pushed down until it separated from the dilator and contacted the bone. The dilator was removed while keeping the guidewire within the hands and the cannula was in place. The suitable sized cannulated self-drilling tap was advanced along the guidewire and into the cannula. While controlling the cannula, the self-drilling tap was advanced over the guidewire inside the pedicle by moving the tap in a clockwise direction. The marks on the proximal tap can be used to determine its depth and the suitable length of the screw. While tapping, it was important being careful in order to avoid unintended guidewire displacement. The tap could not be advanced beyond the tip of the guidewire to avoid unintentional wire removal. Caution should be taken not to displace the guidewire while advancing the tap. Fluoroscopy was used for monitoring how deep the tap was and ensuring the guidewire is not advanced. The appropriate length, diameter, and type of screw were chosen. After insertion

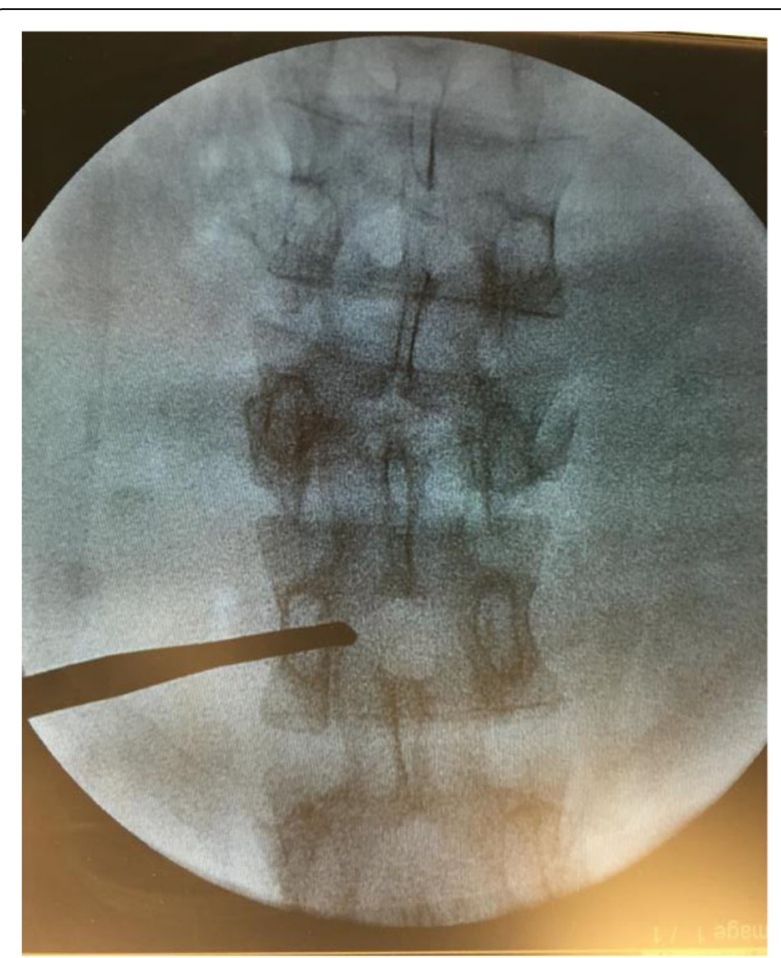

Fig. 5 Pedicles were tapped with a tap cannula from the lateral pedicular margin until it reached the medial margin of the pedicle in AP view.

of the suitable polyaxial driver into the assembly, this combined instrument was threaded into the screw head with rotation clockwise until it stopped. The screw shank should be aligned with the extended tabs, and the motion of the screw should be locked. The combined instrument having the screw was guided over a guidewire till the pedicle and polyaxial screw was threaded into the pedicle. The guidewire was removed when the screw got through the pedicle and entered the body. While inserting the screw inside the pedicle, the markers were monitored on the guidewire for avoiding unintended displacement (Figs. 6, 7, and 8). After the insertion of the screw to the desired depth, the polyaxial driver was removed by moving the handle in a counterclockwise direction while extended tab assembly was firmly held. The polyaxial capability was verified by handling the screw extension. The length of each screw was set properly, and that was verified with lateral fluoroscopy. The length of the rod was measured by reading it at the top of the caliper. Depending on the spine curvatures, the straight, lordosed, or kyphosed rod was selected. The rod holder was parallel to the skin surface, and the rod was perpendicular to the skin (parallel to the axis of the slots of extension). The rod was inserted in the cephalad slot of the extension and its tip put within the closed screw extension. The distal end of the rod was advanced straight down to be below the fascia and touch the top 


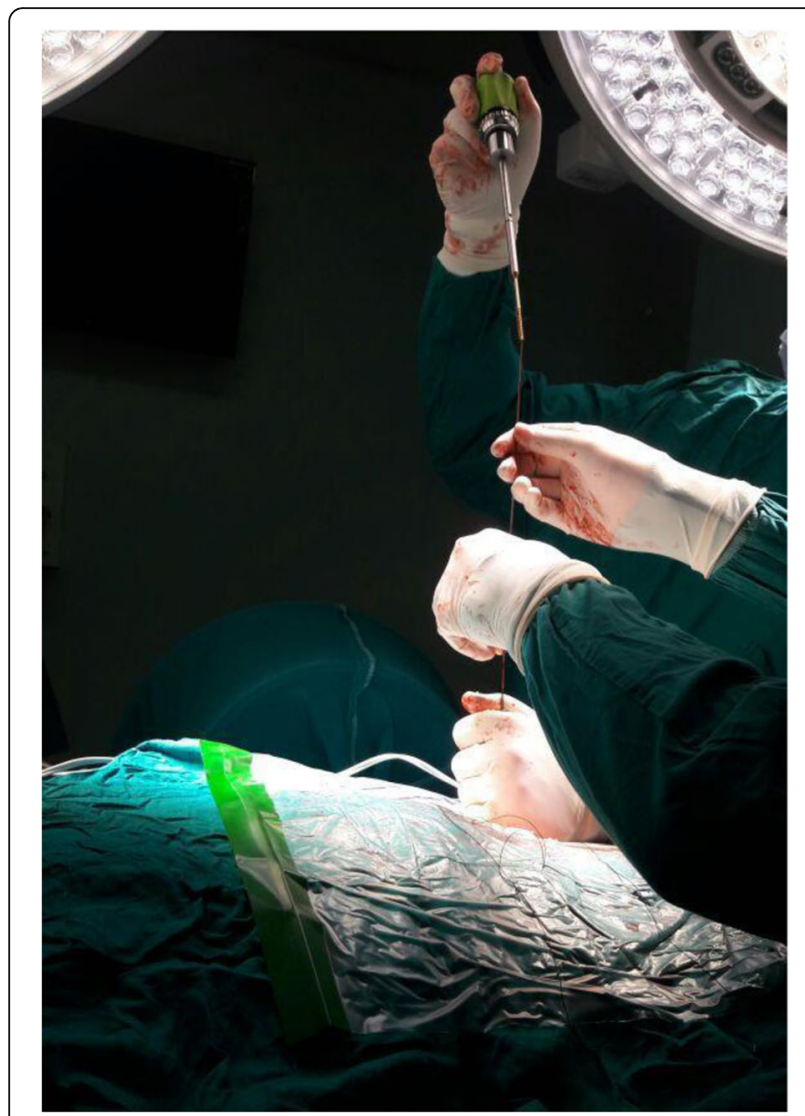

Fig. 6 Usage of a self-drilling cannulated tap

of the screw head. The rod holder was rotated superiorly approximately $45^{\circ}$ and guided by the tip of the rod in each successive extension. The rod was verified to be in the extension by rotating the extension about its axis. The nuts were placed. We can do compression or distraction by distraction and compression forceps. Before the rod holder was removed, the proximal end of the rod should be confirmed radiologically if it was completely seated inside the screw head with approximately $5 \mathrm{~mm}$ overhanging from that head (Figs. 9 and 10). For final tightening/counter-torque, screw extension was removed and fascia and skin were closed (Fig. 11).

\section{Pre- and post-procedural evaluation \\ Clinical assessment}

a) Neurological status: determined by measuring immediate postoperative American Spinal Injury Association (ASIA) score (Table 3) 12 months postoperatively.

b) Prolo economic and functional rating scale 12 months following surgery (Fig. 12). The individual economic and functional statuses were rated by the patients and the final patient's score represented the

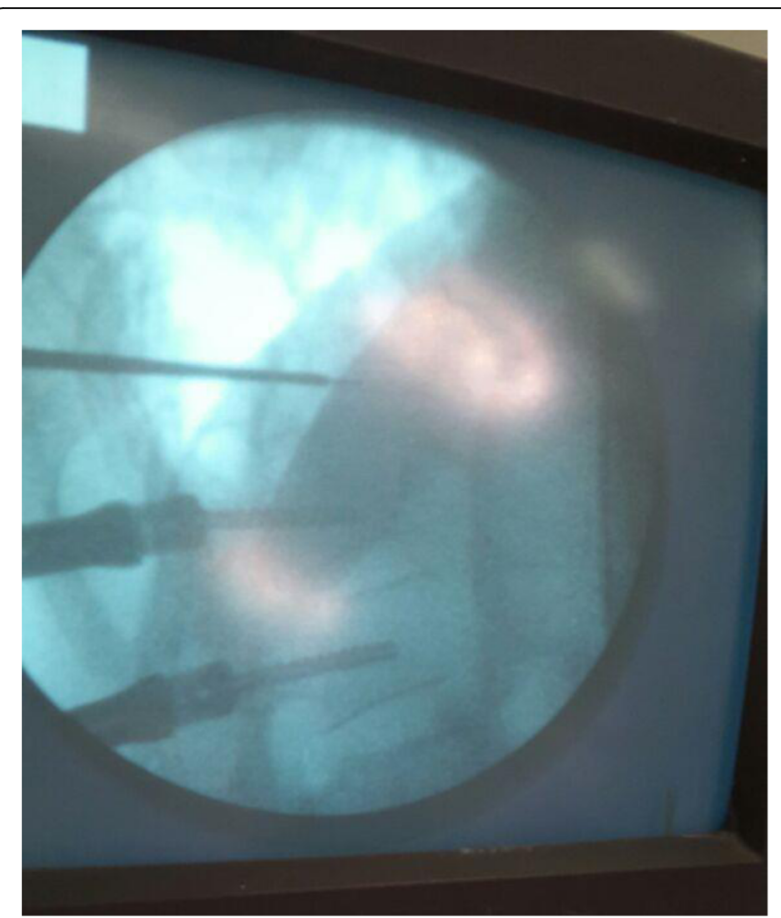

Fig. 7 C-arm gave lateral view to show transpedicular screws and tap cannula

sum of his activity and pain scores (ranging from 2 to 10$)$.

c) Cosmesis: evaluated by the patient and an independent surgeon using a visual analog scale ranging from 0 (very poor) to 10 (excellent), and the scores are calculated and their mean is obtained (Fig. 13). The final cosmesis score is the average of the patient's and the independent surgeon's scores.

\section{Radiographic assessment}

Radiographic assessment was done by measuring the difference in the mean Cobb angle before and after surgery and comparing the average correction obtained by the technique. Cobb angle is measured for comparison early, 3 months, 6 months, and 12 months postoperatively (Fig. 14). For radiological assessment for fusion, CT is the standard for noninvasive assessment of spinal fusion. Fine-cut imaging, multiplanar reconstruction, and metal artifact reduction have increased the ability to assess fusion on CT. The following patients' data were gathered for analysis: age, sex, mode of trauma, level of injury, ASIA impairment score, preoperative Cobb angle, timing of surgery, length of operation, number of screws, blood loss, intraoperative complications, postoperative ASIA score, Prolo scale, cosmesis score, postoperative Cobb angle, mechanical stability, and fusion at 12 months. 


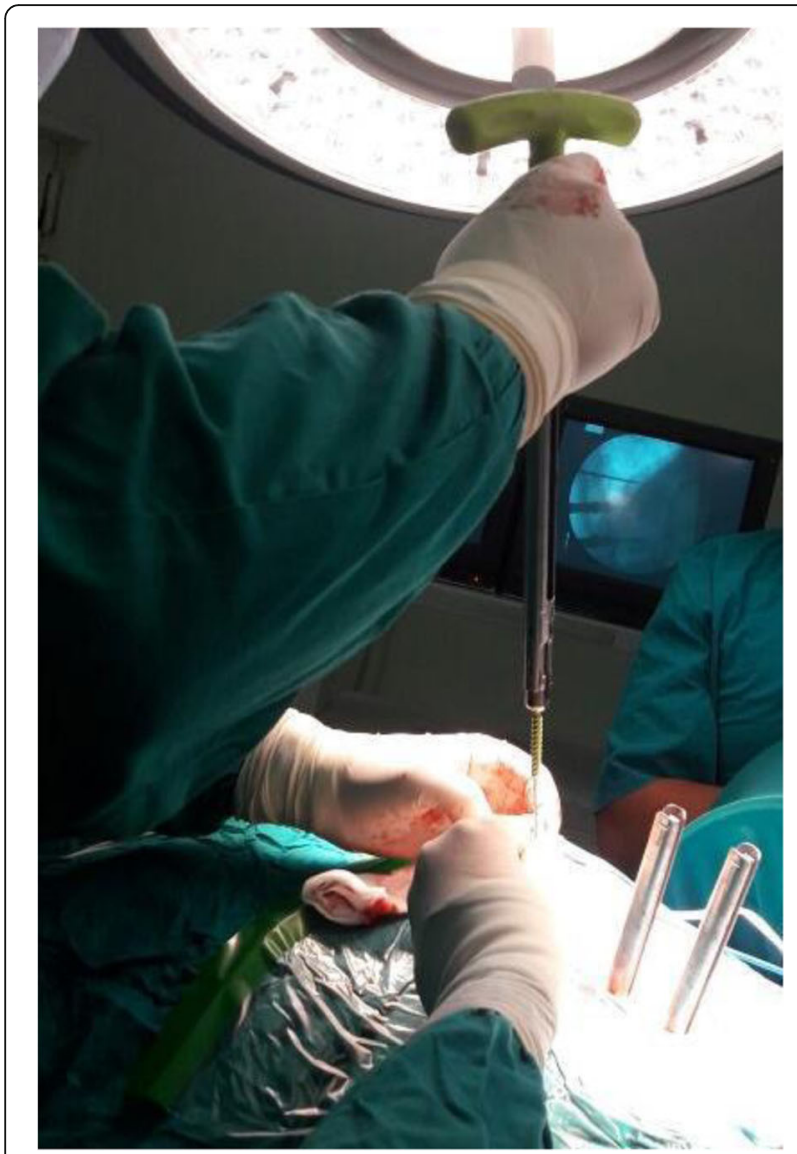

Fig. 8 A screw driver with its screw getting through cannulated polyaxial extensions

\section{Statistical analysis}

The collected data was coded, processed, and analyzed using the SPSS program (version 17) for Windows. The appropriate statistical tests will use discipline analysis using mean $\pm \mathrm{SD}$ for parametric continuous data, median and interquartile range for non-parametric continuous data, and numbers and proportions for description of categorical data.

\section{Results}

This study was conducted in Mansoura Emergency Hospital by operating on 20 cases with the diagnosis of thoracolumbar fractures. The cases underwent percutaneous transpedicular fixations. The age of patients included in our study ranged from 20 to 49 years, with mean age 33.85 years and a standard deviation of \pm 9.09 years. Three fifths of the patients in this study were males (60\%), and two fifths of them were females (40\%). Thirteen patients $(65 \%)$ were married. Sixty-five percent of cases (13 patients) were current smokers and 35\% (7 patients) were either none or ex-smokers. As regards the occupations of patients, the majority were farmers (six cases, 30\%), five patients were lawyers (25\%), four

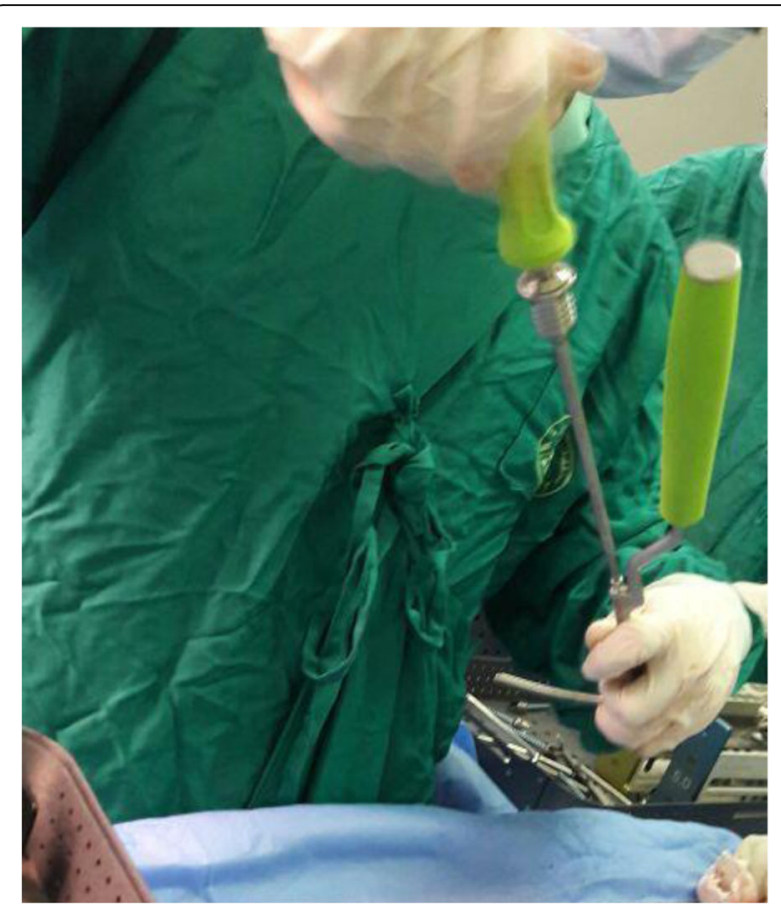

Fig. 9 A rod attached to the rod holder

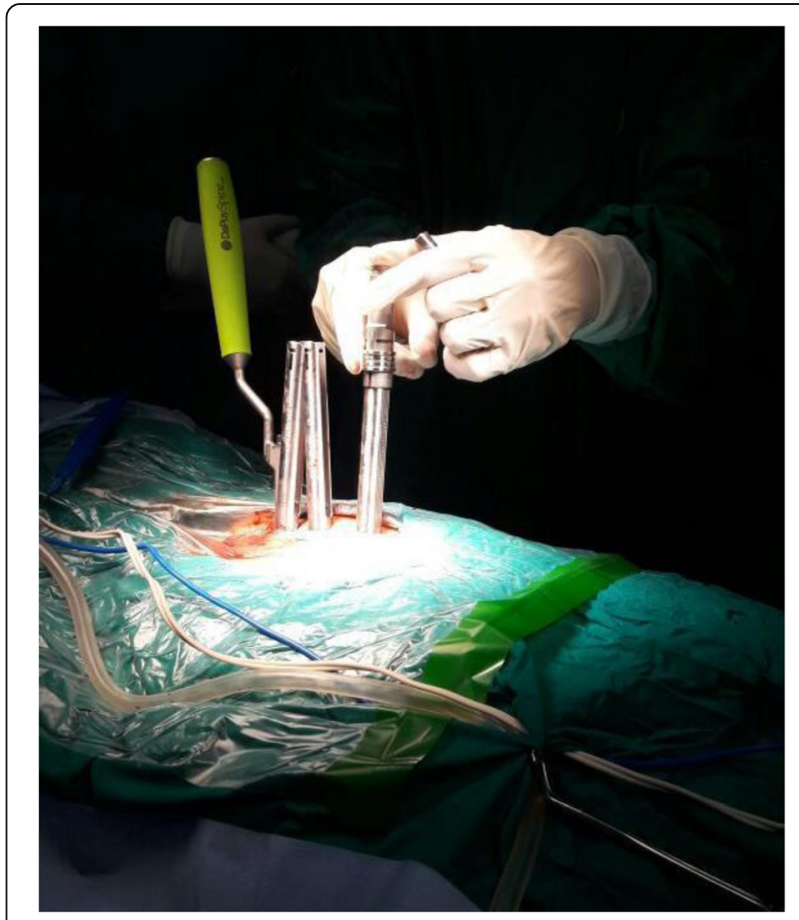

Fig. 10 Rod holder removal 


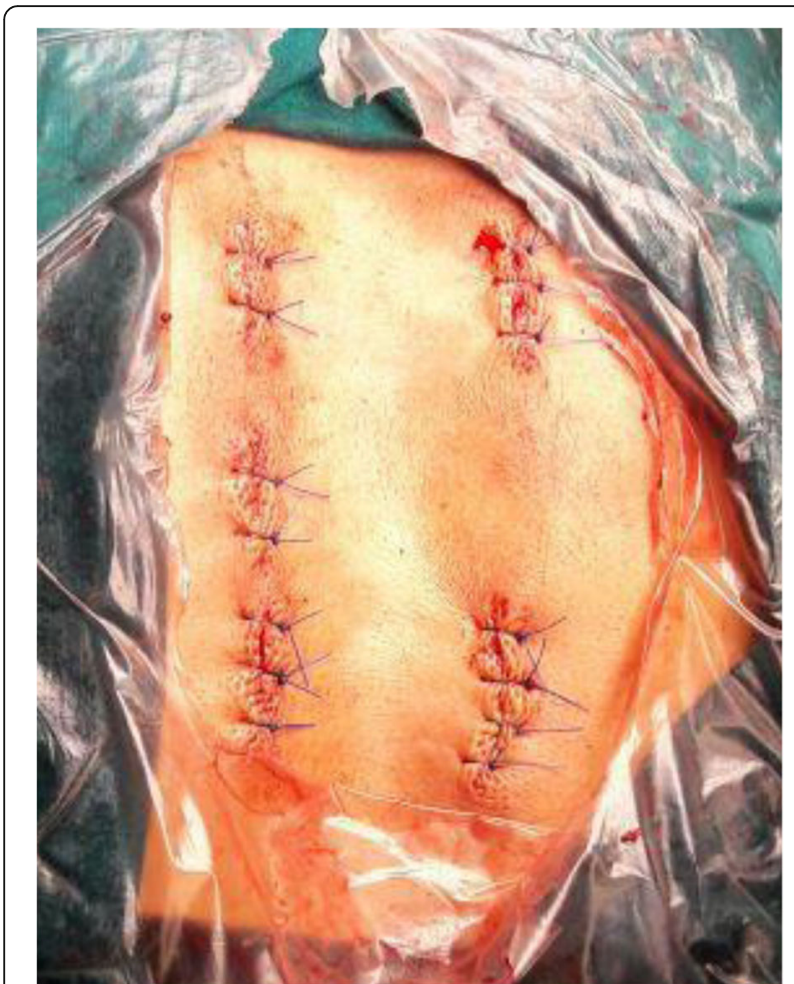

Fig. 11 Fascia and skin closure

patients were accountants (20\%), three patients were students (15\%), and two patients were housewives (10\%). According to the mode of injury, $60 \%$ (12 patients) had been injured due to motor vehicle accidents and $40 \%$ (8 patients) had fallen from height. The time of presentation to our hospital after trauma ranged from 1 to $24 \mathrm{~h}$, with median time of $6.00 \mathrm{~h}$ and IQR (interquartile range) of $7.25 \mathrm{~h}$ (non-parametric data were described as median and interquartile range, a way to describe distribution of data when data is non-Gaussian and IQR is a measure of where the bulk of values lie). As regards the level of fractures in the lumbar spines, the second lumbar vertebra showed the majority of fractures of cases (8 cases representing 2/5 cases) followed by lumbar 1 fracture in 6 cases, dorsal 12 fracture in 6 cases, and lumbar 3 fracture in 4 patients. Four cases were with double-level fractures, two of them were lumbar 1 and 2 and the other two cases were lumbar 2 and 3. The cases were prepared for surgery as early as possible. Depending on the patient condition and some administrative rules, the timing of surgical interference varied from 12 to $24 \mathrm{~h}$ posttrauma. The mean timing of interference was 17.95 $\mathrm{h}$ with standard deviation of $\pm 3.58 \mathrm{~h}$. The number of screws inserted ranged from 4 to 6 screws/case with mean 5.11 screws and standard deviation of \pm 0.81 screws. Ten cases were fixed by six screws (T12 in L1 in L2), four cases were fixed by five screws (T12 in L1 in L2), four cases were fixed by six screws ( L1 in L2 in L3), and the last two cases were fixed by four screws (L2 in L3). The length of the procedure varied from 120 to 180 min with mean time of $154.50 \mathrm{~min}$ and standard deviation of $\pm 24.38 \mathrm{~min}$. There was no significant blood loss in all cases. The volume of blood loss ranged from 150 to $200 \mathrm{cc}$ with mean loss of $174.25 \mathrm{cc}$ and standard deviation of \pm 19.42 . No major intraoperative complications happened in our study cases. Six cases had only one laterally malpositioned screw each (Fig. 15). The TLICS score of patients ranged from 2 to 5 with a mean score of 3.45 and standard deviation of \pm 1.28 while the load-sharing classification score was either 3 or 4 with mean score of 3.5 and standard deviation of \pm 0.51 . All cases were ASIA score E preoperatively (normal motor and sensory functions) and remained so postoperatively till the end of the follow-up period. All cases returned to their previous activity without limitations (E5). Those who were completely pain free (F5) were 15 patients. Only five patients were suffering from moderate pain (F4). The Prolo scale was either 9 or 10 with mean of 9.60 and standard deviation of \pm 0.51 . The lowest patients' cosmesis visual analog scale (VAS) score was 7 in one case and the highest was 10 in one case, while the lowest physician's cosmesis VAS score was 7 in 4 patients and the highest was 10 in one case. The mean (final) VAS score ranged from 7 to 10 according to patients and physician scores. The mean of patients' VAS score for cosmesis was 8.55 with standard deviation of + 0.83 while the mean of physician's VAS score was 8.35 with standard deviation of +0.79 . The mean of final VAS score was 8.45 with standard deviation of +0.81

Table 3 ASIA Impairment Scale [10]

\begin{tabular}{ll}
\hline Grade & Description \\
\hline A Complete & No sensory or motor function is preserved in the sacral segments S4-S5 \\
B Incomplete & Sensory but not motor function is preserved below the neurological level and extends through the sacral segments S4-S5 \\
C Incomplete & $\begin{array}{l}\text { Motor function is preserved below the neurological level, and the majority of key muscles below the neurological level have } \\
\text { a muscle grade less than } 3\end{array}$ \\
D Incomplete & $\begin{array}{l}\text { Motor function is preserved below the neurological level, and the majority of key muscles below the neurological level have } \\
\text { a muscle grade greater than or equal to } 3\end{array}$ \\
E Normal & Sensory and motor function is normal \\
\hline
\end{tabular}




\begin{tabular}{cl}
\hline Score & Criteria \\
\hline Economic status \\
1 & Completely invalid \\
2 & No gainful occupation, including ability to do housework or retirement activities \\
3 & Ability to work but not at previous occupation \\
4 & Working at previous occupation part time or w/ limited status \\
5 & Able to work at previous occupation w/ no restrictions \\
Functional (social) status \\
1 & Total incapacity (worse than preop) \\
2 & Mild to moderate level of low-back pain \&/or sciatica (or pain same as preop but able to perform all \\
3 & Laily tasks of living) \\
4 & Now level of pain \& able to perform all activities except sports \\
5 & Complete recovery, no episodes of recurrent low-back pain, \& able to perform all previous sports activities \\
\hline
\end{tabular}

Fig. 12 Prolo economic and functional rating scale

(Fig. 16). The Cobb angles registered preoperatively ranged from 17 to $25^{\circ}$. After surgical correction and fixation, the angles ranged from 13 to $21^{\circ}$ in the immediate postoperative images, giving angles of correction ranging from 0 to $6^{\circ}$ (Fig. 17, Table 4).

The postoperative hospital stay of the patients ranged from 19 to $48 \mathrm{~h}$ and mean hospital stay was 28.55 with a standard deviation of $\pm 7.34 \mathrm{~h}$. Fusion was evaluated at 3,6 , and 12 months postoperatively (Tables 1,2 ). There was no significant difference in mean age between fusion and non-fusion groups at 12 months of fixed groups (Student's $t$ test, $P$ value $=0.912$, Table 5). Moreover, comparing fusion rates at 12 months in both males and females revealed no significant difference (Fisher's exact test, $P$ value $=1.000$ ). We found that at 3 months postoperatively, there was no fusion at all in smokers and non-smokers (Fig. 18). However, at 6 months, fusion was significantly lower among the smokers (28.6\%) to non-smokers $(84.4 \%)$ (Fisher's exact test, $P$ value $=$ 0.022). On the contrary, the fusion rates at 12 months showed no significant difference between smokers and non-smokers (Fisher's exact test, $P$ value $=0.483$ ) (Fig. 19). TLICS score was found to be a statistically significant factor associated with fusion after 6 months. The fused group (13 cases) had lower TLICS score (mean rank $=7.85$ ) compared to the non-fused group (mean rank $=15.43)($ Mann-Whitney test, $P$ value $=0.041)$. The immediate postoperative Cobb angle $\left(17.75 \pm 2.36^{\circ}\right)$ was found to be significantly lower than the preoperative Cobb angle (21.05 \pm $2.28^{\circ}$ ) (Wilcoxon test, $P$ value $=0.001$ ) indicating good kyphosis correction. However, there was no significant difference in Cobb angles at 3, 6, and 12 months revealing no significant loss of Cobb angle correction over the follow-up period (Friedman test, $P$ value $=0.09$ ). Moreover, there was no significant association between fusion after 12 months and preoperative Cobb angle in our study (Student's $t$ test, $P$ value $=0.812$.

There was no significant correlation between cosmesis and age (Spearman's rho test, $P$ value $=0.651$ and correlation coefficient $=0.112$ ), sex (Mann-Whitney test, $P$ value $=0.811)$, or smoking $($ Mann-Whitney test, $P$ value $=0.841)$. Prolo scale at 12 months was not significantly different among smokers and non-smokers (Mann-Whitney test, $P$ value $=0.262$ ). Moreover, the screw malposition was also found to be a non-significant factor associated with Prolo scale (Mann-Whitney test, $P$ value $=$ 0.691). There was no significant correlation between Prolo scale and age (Spearman's rho test, $P$ value $=0.455$ ) or sex (Mann-Whitney test, $P$ value $=0.276)$. However, there was a relative correlation between Prolo scale and both of TLICS score (Spearman's rho test, $P$ value $=0.062$ ) and load-sharing scores (Spearman's rho test, $P$ value $=0.074$ )

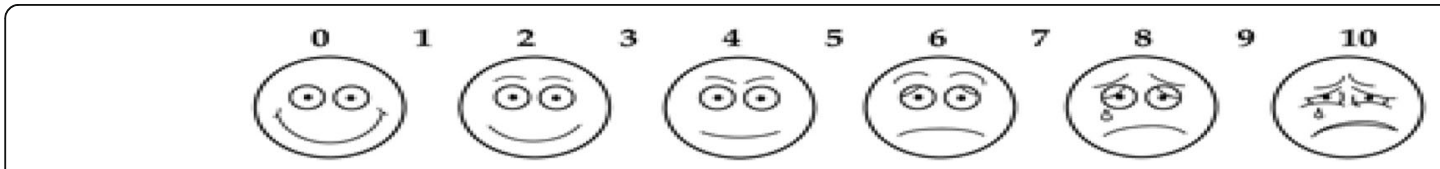

Fig. 13 Visual analog scale for cosmetic appearance of the surgical wound 


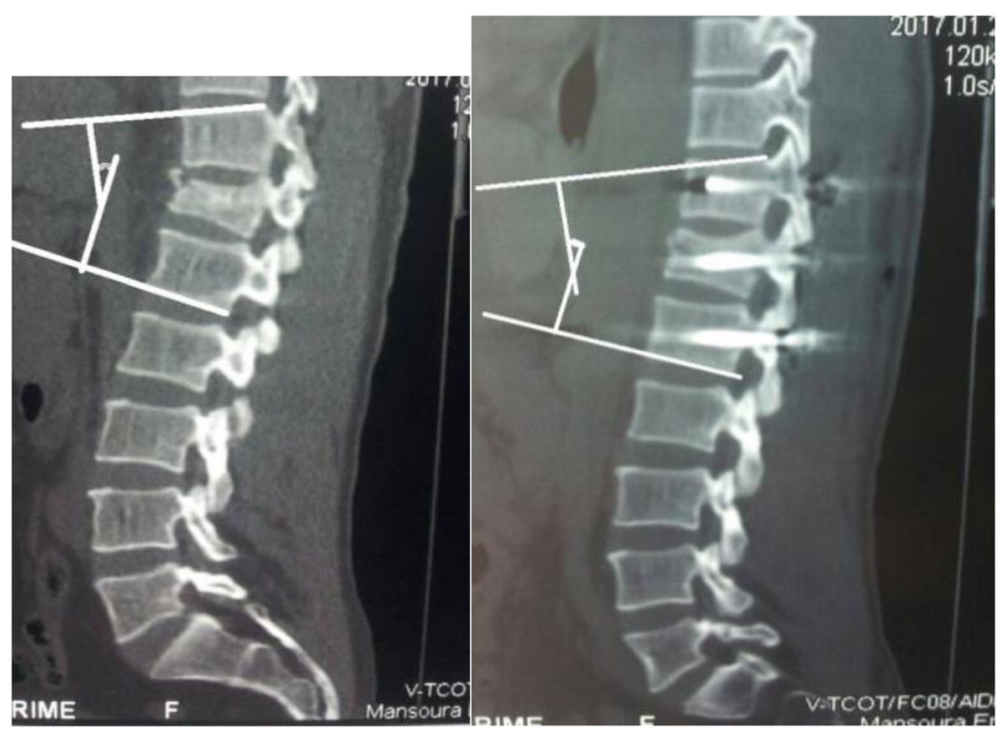

Fig. 14 Pre- and postoperative Cobb angle

\section{Discussion}

Pedicle screw instrumentation enables a rigid construct to promote stability and fusion for numerous spinal pathologies including trauma, tumors, deformity, and degenerative disease [3]. Traditionally, traumatic thoracolumbar fractures are treated with open technique of spinal fixation. Open techniques usually result in extensive muscle dissection from the midline till the pedicular entry points which induce pain by activating peripheral receptors that transmit the information through the

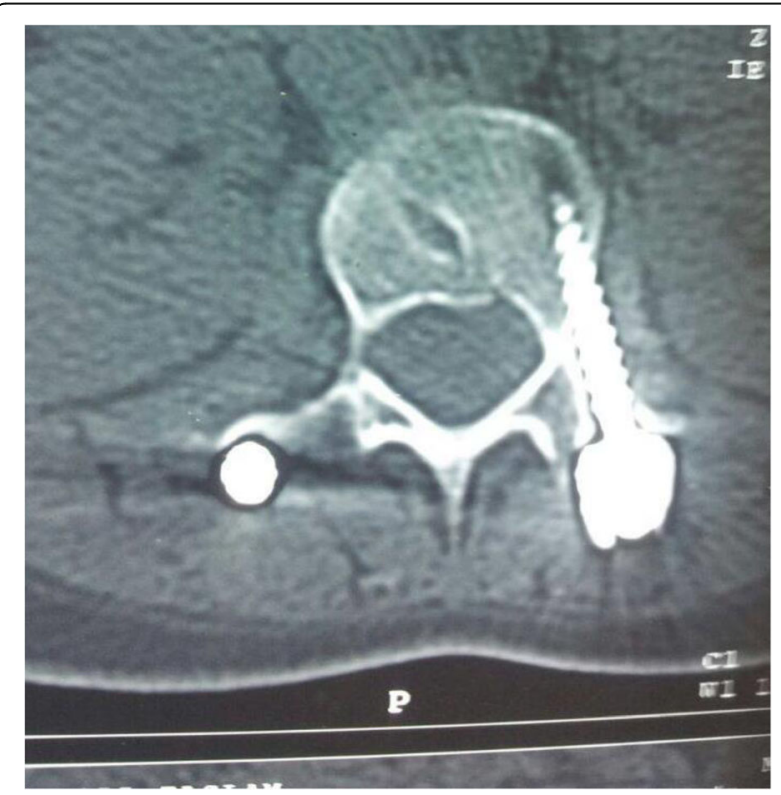

Fig. 15 One of six cases show a left lateral malpositioned screw in $L 2$ spinal cord to the brain where it is modulated [11]. Periosteal pain is believed to be the most severe as the periosteum has the lowest pain threshold nerve fibers of the deep somatic structures. Standard midline posterior spinal approaches have been shown to cause significant muscle morbidity resulting from iatrogenic muscle denervation (particularly with exposure lateral to the facet), increased intramuscular pressure, ischemia, and revascularization injury. All of these effects can lead to paraspinal muscular atrophy and scarring [12]. There has been a paradigm shift in treating these fractures through MIS (minimally invasive surgery) with less tissue damage due to direct trajectory and minimal tissue dissection and, hence, minimal surgical inflammatory response (inflammatory mediators such as interleukins, cytokines, and prostaglandins) compared to conventional surgery [13]. Minimally invasive percutaneous transpedicular screw fixation showed a significant role in minimizing approach-related morbidity [5]. The advantages of this minimally invasive surgery include small skin incisions; minimal paraspinal muscle dissection; sparing the posterior elements that are lamina, spinous process, supraspinous and interspinous ligaments, and paravertebral muscles; less intraoperative bleeding; superior postoperative muscle strength; less exposure to anesthetic drugs; quick recovery; early mobilization; and shorter hospitalization stay [6]. More than $70 \%$ of vertebral fractures admitted during the period of our study were located in the upper lumbar region. This made the upper lumbar region the most commonly affected region among spinal fractures. In a study by Scoliosis Research Society, the upper lumbar region was reported to be the most frequently affected site (52\%) in spine injuries, followed by the lumbar site (L2-L5) with a rate of 


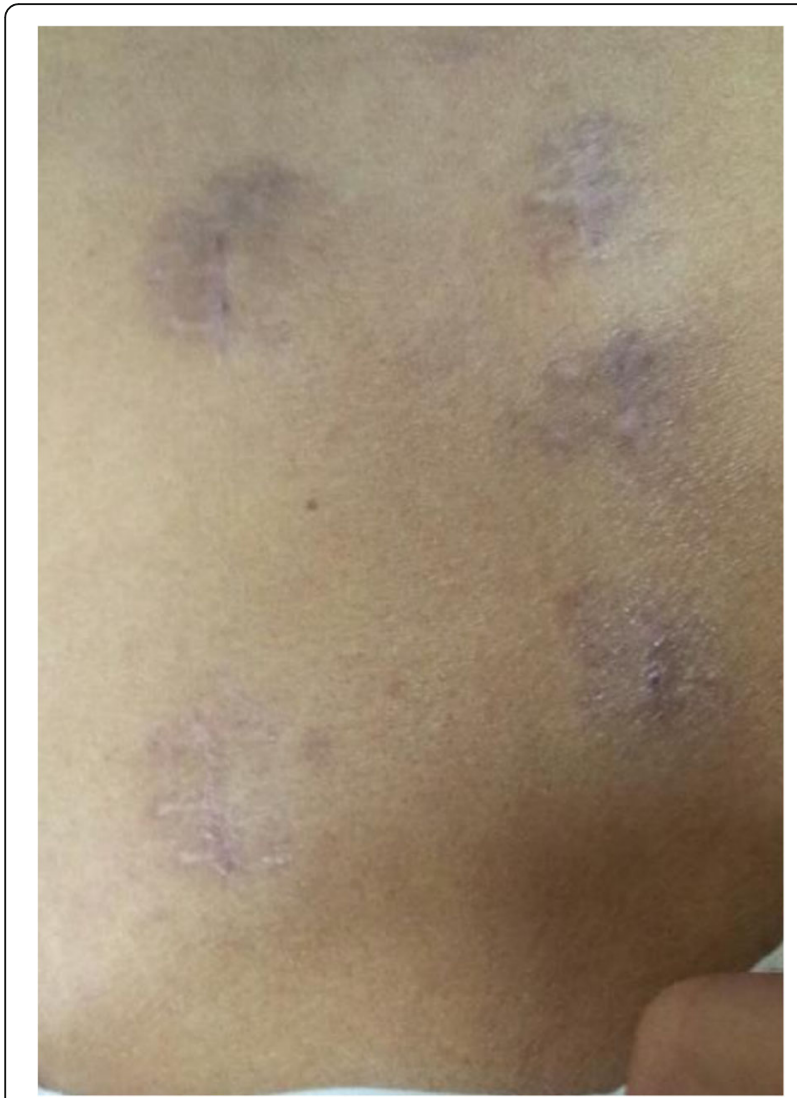

Fig. 16 Postoperative photo of wound after 3 months in a case of dorsal 12 fracture fixed by 5 screws D $11 \times$ D $12 \times$ L1. The patient VAS score was 8 and the physician score was 7, so the mean VAS score was 7.5 .
$32 \%$, and the thoracic site (T1-T10) with a rate of $16 \%$. Krompinger et al. [14] reported that most frequently injured sites were the upper lumbar region (48\%), lower lumbar region (34\%), and thoracic region (18\%), respectively. The upper lumbar region was once more the site most frequently involved in a study by Keen [15] and a another study done by Erturer et al. [16] where the upper lumbar region was involved in about $57.2 \%$ of spinal fractures. Our results thus agreed with others, despite in different ratios, that the upper lumbar region was the most common site of spinal fractures. The percentage of upper lumbar region involvement was higher $(70 \%)$ in our study. The reasons for the frequent injury at the level of the upper lumbar region were the absence of the protective role of the rib cage at this site, progression of lumbar lordosis to thoracic kyphosis, and the location of facet joints coronally in the thoracic region and sagittally in the lumbar region, resulting in facet joint maladjustment [17]. The mean age of patients in our study was 33.85 years ranging from 20 to 49 years. This age correlated with most series dealing with vertebral fractures where mean ages lied in the first half of 30s [18]. There were 12 males $(60 \%)$ and 8 females $(40 \%)$ in our study. Males therefore were 1.5 times more common to develop lumbar fractures than females. The male predominance in our study agreed with the literature. However, male-to-female ratio in our study (3:2) differed from other studies. It was far different from Indian epidemiological studies [19] where in the rural setup, the ratio of male to female ranged from 9:1 to 13.5:1. Another Indian study done by Upendra et al. [20] reported a ratio that approximated western literature where male-to-female ratio was 4.5:1. Many western studies reported that men are two to four times more likely to have these fractures compared to

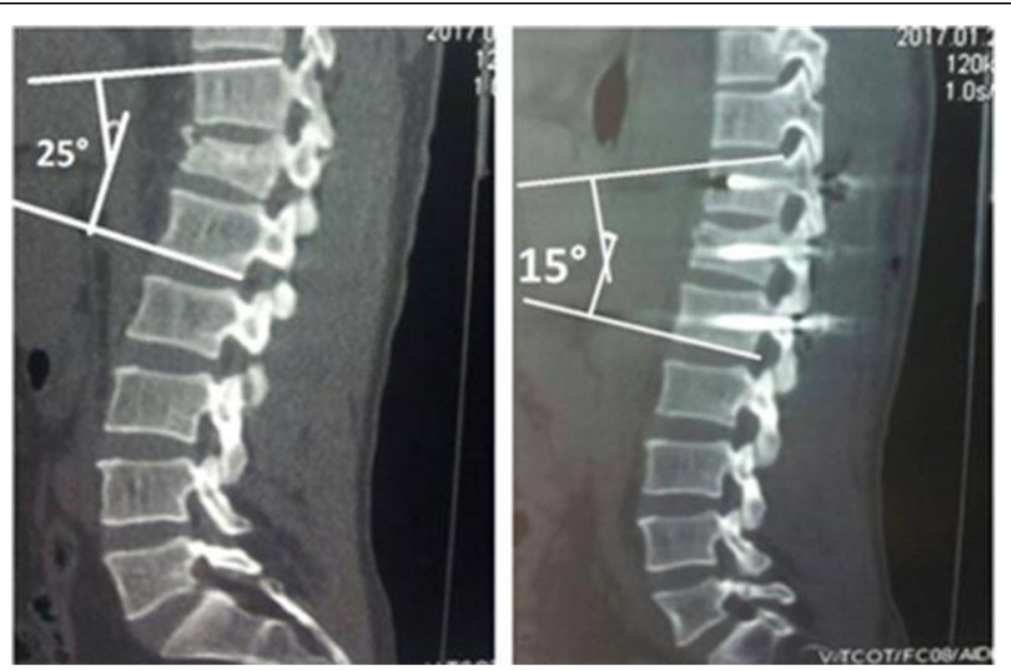

Fig. 17 Preoperative Cobb angle $\left(25^{\circ}\right)$ and immediate postoperative Cobb angle $\left(15^{\circ}\right)$ with correction angle $10^{\circ}$ 
Table 4 Cobb angle before and after surgery in the studied cases

\begin{tabular}{lll}
\hline & Range & Mean \pm SD \\
\hline Preoperative Cobb angle & 17 to 25 & $21.05 \pm 2.98$ \\
Immediate postoperative Cobb angle & 13 to 21 & $17.75 \pm 2.36$ \\
Correction angle & 0 to 6 & $3.30 \pm 1.38$ \\
Cobb angle at 3 months & 12 to 21 & $17.30 \pm 2.40$ \\
Cobb angle at 6 months & 13 to 22 & $17.45 \pm 2.54$ \\
Cobb angle at 12 months & 13 to 22 & $17.85 \pm 2.55$ \\
\hline
\end{tabular}

women [21]. It seems that the community rules and traditions play an important role in determining sex preponderance in spinal fractures. In conservative communities where females are mostly housewives and do not have much outdoor activities, females are much less involved in spinal injuries. In western communities where females are nearly as much active outdoors as males, the female-tomale ratio is bigger. The sex distribution in our study gave ratios that approximated those of western literature, something which might reflect social and economic changes that

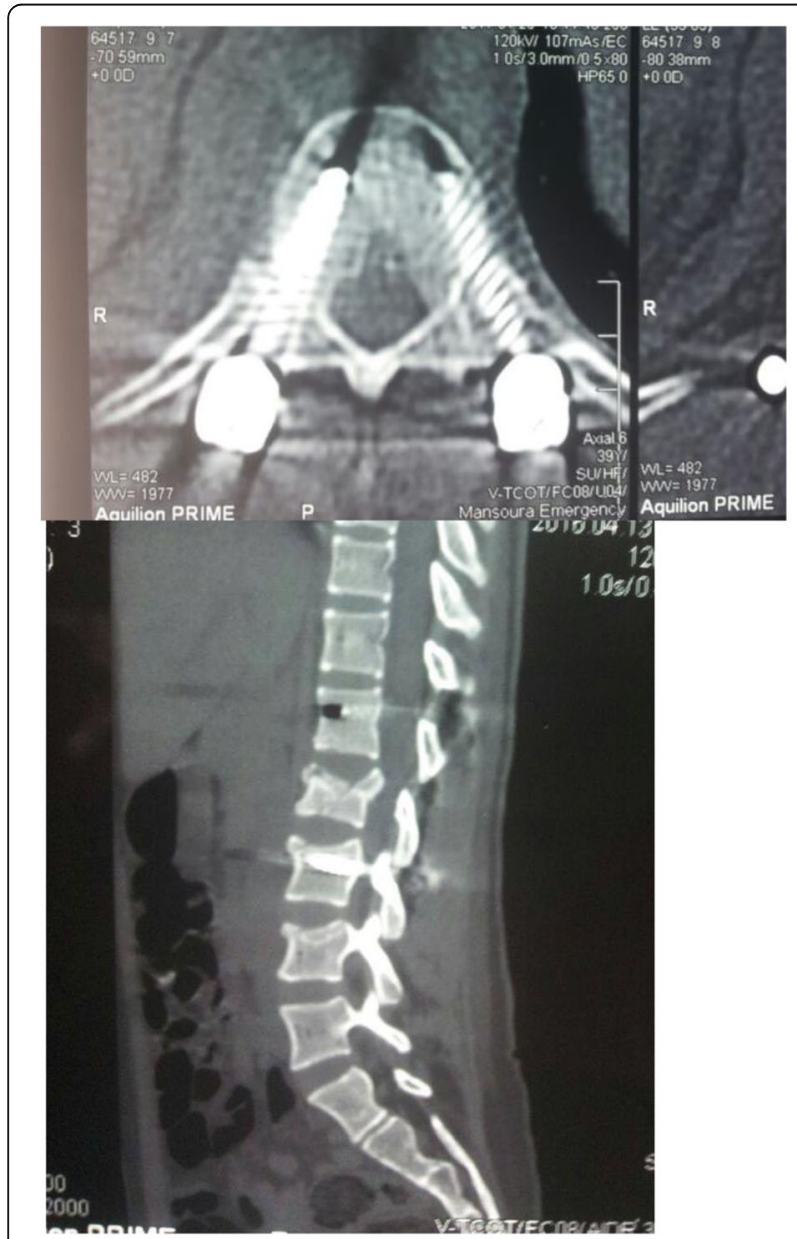

Fig. 18 No fusion after 3 months

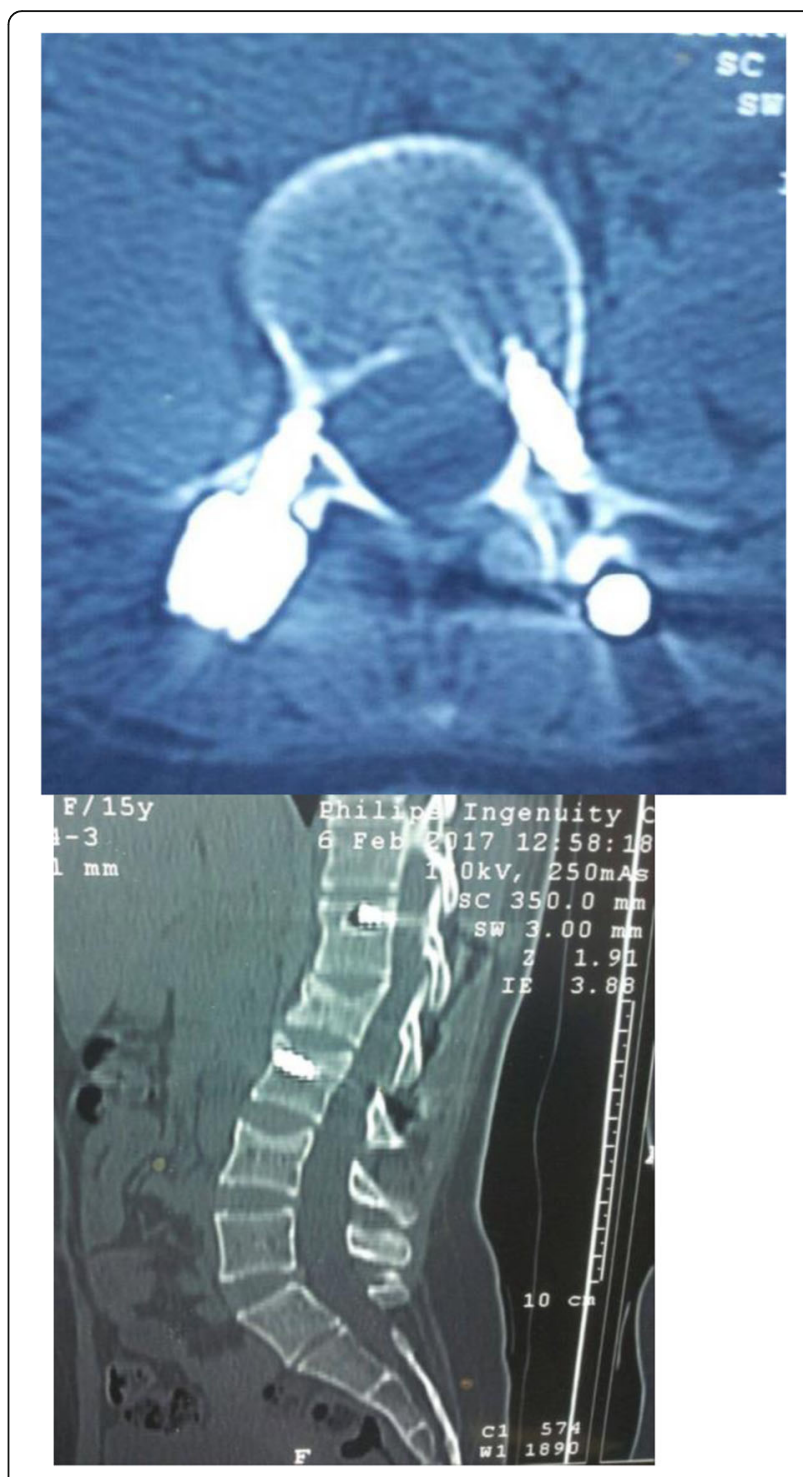

Fig. 19 Fusion after 12 months

happened in our community, but should be interpreted with caution as the patient sample was small. Vertebral fractures are usually due to high-energy traumas like falls from height and motor vehicle accidents [22]. In our study, fall from height was the most common mode of injury (80\%), followed by motor vehicle accidents (15\%), while road traffic accident was represented by only one patient

Table 5 Fusion

\begin{tabular}{ll}
\hline & Patients \\
\hline Fusion after 3 months & $100 \%$ no fusion \\
Fusion after 6 months & 13 cases (65\%) fused \\
& 7 cases (35\%) no fusion \\
Fusion after 12 months & 17 cases (85\%) fused \\
& 3 cases (15\%) no fusion \\
\hline
\end{tabular}


(5\%). In Indian studies, fall from height was reported as the most common mode of injury [19], while in western literature, several studies reported that motor vehicle accidents were by far the most common etiology of spinal fractures [23]. Although our patient sample was too small to generalize our results, taking the community similarities into consideration, the lack of safety measures and guidelines for those who work at heights and the negligence in wearing safety belts may be the cause of making falls to be the most common mode of spinal injuries in the Indian and our communities. These measures are strict in western countries. It seems clear that application of such measures and guidelines in our community can result in a drop in the number of falls and thus spinal injuries. However, motor vehicle accidents represented a major mode of vertebral injuries in our sample, as well as western communities. Negligence in the use of seatbelts even in these communities was reported to be responsible for about $2 / 3$ of motor vehicle spinal injuries [24]. As regards the level of fractures in the thoracolumbar spines, the second lumbar vertebra showed the majority of fractures (8 cases representing $2 / 5$ cases) followed by lumbar 1 fracture in 6 cases, dorsal 12 fracture in 6 cases, and lumbar 3 fracture in 4 patients. Four cases were with double-level fractures, two of them were lumbar 1 and 2 and the other two cases were lumbar 2 and 3.The first lumbar vertebra is typically the most commonly fractured in the literature [25]. This discrepancy may be partly due to involvement of L2 vertebral level among the definition of the thoracolumbar junction in our study. It may be also affected by the relatively small sample of patients available to analyze the frequency of fractured levels or may be miscounting by the rudimentary rib. The length of the procedure varied from 120 to $180 \mathrm{~min}$ with mean time $154.50 \mathrm{~min}$. Merom et al. reported that with shortsegment fixation, the operative time for percutaneous fixation was 73 to $85 \mathrm{~min}$ [26]. Ni et al. reported an average operative time of $70 \mathrm{~min}$ for short-segment fixation [27]. In a series of 76 patients (16 with long-segment fixation), Schmidt et al. reported an average operative time of 47 min. In $56 \%$ of these patients, the total operative time was between 22 and $36 \mathrm{~min}$ [25]. In our study, the operative time ranged from 120 to $180 \mathrm{~min}$ which reflected the start of our learning curve. Pelegri et al. reported a 3.8\% rate of misplacement out of 50 screws; in one case, an open revision had to be performed because of neurological problems [28]. Ni et al. found that $6.7 \%$ of 104 screws implanted were misplaced, but there were no neurological complications [27]. Korovessis et al. reported that out of 180 screws implanted percutaneously for fracture fixation, three screws were placed too medially, but these had no clinical consequences and they occurred early in his learning process [29]. In comparison to the previous studies, we found that $9 \%$ of 80 screws inserted were laterally misplaced with no neurological complications. $\mathrm{Ni}$ et al. reported one superficial infection out of 36 patients having percutaneous fixation; the infection was treated with antibiotics alone [27]. Schmidt et al. had no infections in 76 patients, but one revision was performed for paravertebral haematoma [25]. Merom et al. observed only one superficial infection in ten cases of open fixation and no infections in ten cases of percutaneous fixation [26]. Palmisani et al. had one infection that required instrumentation removal out of 64 percutaneous fixation cases [30]. Overall, these published studies reported a fairly low infection rate when compared to infection rates for open procedures, which were known to be around $3.1 \%$ and could go up to $10 \%$ [31]. Fortunately, we had no infection in our cases, which may be explained by a small number of cases. Lee et al. showed a loss of $3.1^{\circ}$ in the percutaneous group versus $3.5^{\circ}$ in the open group for local kyphosis angle [8]. Dong et al. concluded that the percutaneous and open techniques did not result in significant differences in the curative effect or radiologic measurement data and that both approaches achieve a good curative effect [32]. These studies matched with ours as we showed only a loss of $3.3^{\circ}$. We advocated two ways for comparing the outcome in our study: the clinical and functional assessment and the radiological assessment. Although some studies included clinical outcome measures such as pain and functioning, many studies focused on radiological outcome only. One could argue that radiological changes are only relevant if they are strongly associated with changes in clinical outcomes [33]. Radiographic measurement of angulation on the sagittal plane (Cobb angle) of the fractured vertebral segment has been extensively used for the evaluation and postoperative follow-up of patients [34]. All cases returned to their previous activity without limitations (E5). Those who were completely pain free (F5) were 15 . Only five patients were suffering from moderate pain (F4). The functional and economic outcome was significant in our patients. Less number of incisions, scars (small scars of approximately $2 \mathrm{~cm}$ ), and minimal soft tissue damage are encountered. All patients were satisfied from cosmetic appearance of the scar. In our study, the mean of final VAS score for cosmesis was 8.45 which was nearly equal to Merom [26] as the mean of final VAS score for cosmesis was 8.5. In the Merom et al. study, patients treated with percutaneous fixation were able to walk 1 or 2 days after the surgery [26]. Our patients ambulated at a range from 6 to $12 \mathrm{~h}$ and that was superior to previous literature.

\section{Conclusions}

We explored the feasibility, safety, efficacy, and cosmesis of percutaneous approach and compared these aspects to those of other studies. A team with growing experience in this technique carried on the surgical procedure, and independent physicians carried out the follow-up (to avoid conflict of interest). Cases were followed up for 1 
year and results were collected regarding patient's demographic data, neurological status, functional outcome, signs of fusion, and correction gain on radiological studies. We found our study sharing others in some results and disagree in some. The upper lumbar region was the most common site of spinal fractures, the late 20s and early 30 s were the most common age groups, and males were one and a half more commonly affected than females. We shared studies from developing countries that high falls are the most common cause of spinal fractures. We first selected the surgical cases from all patients based on TLICS scoring and neurological status then we used a single method of reconstruction, it includes percutaneous transpedicular screw placement. The amount of blood loss, however, was not found to be different between various studies, and there were no major intraoperative complications with the approach. So, our approach is a feasible, less time-consuming procedure.

By comparing our results with other studies, we found more or less equivalence in terms of neurological recovery, functional outcome, fusion rate, and maintenance of correction gain. However, the cosmesis scores for patients in the study were great.

\section{Abbreviations}

ASIA: American Spinal Injury Association; CSF: Cerebrospinal fluid;

CT: Computed tomography; MRI: Magnetic resonance imaging;

TLICS: Thoracolumbar injury classification and severity; VAS: Visual analog scale

\section{Acknowledgements}

No other person contributed to this article

\section{Authors' contributions}

The corresponding author and co-authors performed all of the procedures, clinical assessment, follow-up of patients, collection of results, statistics, and final editing and are responsible for the study conception and design. The authors read and approved the final manuscript.

\section{Funding}

Nothing to disclose

\section{Availability of data and materials}

Raw data are available

\section{Ethics approval and consent to participate}

Prospective ethics approval was obtained from the Faculty of Mansoura University, Neurosurgery Department, research ethics committee, where the committee approved the study protocol from the ethical point of view. All patients signed an informed consent for the procedure and possible outcomes. The protocol was submitted for approval by the local Institutional Research Board (IRB), Faculty of Medicine, Mansoura University, with a code number (MS/16.04.76).

\section{Consent for publication}

This study reported no personal data for any patients; informed consents were obtained for all patients included in this study for the publishing of results.

None of the patient involved in this study had declined the publication of study results.

\section{Competing interests}

The authors declare that they have no competing interests.
Received: 9 July 2019 Accepted: 16 October 2019

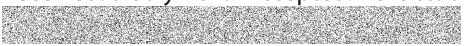

\section{References}

1. Vaccaro $A R, A n H S$, Lin $S$, et al. Noncontiguous injuries of the spine. J Spinal Disord. 1992;5:320-9.

2. Trivedi JM. Spinal trauma: therapy—options and outcomes. Eur J Radiol. 2002:42:127-34.

3. Kanter AS, Mummaneni PV. Minimally invasive spine surgery. Neurosurg Focus. 2008;25:E1.

4. Harris EB, Massey P, Lawrence J, et al. Percutaneous techniques for minimally invasive posterior lumbar fusion. Neurosurg Focus. 2008;25:E12.

5. Rechtine GR, Cahill D. ChrinAM: Treatment of thoracolumbar trauma: comparison of complications of operative versus non-operative treatment. J Spinal Disord. 2009;12:406-9.

6. Selznick LA, Shamji MF, Isaacs RE. Minimally invasive interbody fusion for revision lumbar surgery: technical feasibility and safety. J Spinal Disord Tech. 2009;22:207-13.

7. Oppenheimer JH, DeCastro I, McDonnell DE. Minimally invasive spine technology and minimally invasive spine surgery: a historical review. Neurosurg Focus. 2009;27:E9.

8. Lee JY, Vaccaro AR, Lim MR, et al. Thoracolumbar injury classification and severity score: A new paradigm for the treatment of thoracolumbar spinal trauma. J orthop Sci. 2005;10:671-5.

9. McCormack T, Karaikovic E, Gaines RW. The load-sharing classification of spine fractures. Spine. 1994;19:1741-4.

10. Ditunno JF Jr, Young W, Donovan WH, Creasey G. The international standards booklet for neurological and functional classification of spinal cord injury. American Spinal Injury Association. Paraplegia. 1994;32(2):70-80.

11. Kawaguchi Y, Matsui H, Tsuji H. Back muscle injury after posterior lumbar spine surgery. Part 2: Histologic and histochemical analyses in humans. Spine (Phila Pa 1976). 1994;19:2598-602.

12. Kawaguchi Y, Yabuki S, Styf J, Olmarker K, Rydevik B, Matsui H, et al. Back muscle injury after posterior lumbar spine surgery. Topographic evaluation of intramuscular pressure and blood flow in the porcine back muscle during surgery. Spine (Phila Pa 1976). 1996;21:2683-8.

13. Jackson RK. The long-term effects of wide laminectomy for lumbar disc excision. A review of 130 patients. J Bone Joint Surg Br. 1971;53:609-16.

14. Krompinger WJ, Fredrickson BE, Mino DE, et al. Conservative treatment of fractures of the thoracic and lumbar spine. Orthop Clin North Am. 1986;17: $161-70$.

15. Keene JS. Radiographic evaluation of thoracolumbar fractures. Clin Orthop Relat Res. 1984;189:58-64.

16. Erturer $\mathrm{E}$, Tezer M, Ozturk I. Evaluation of vertebral fractures and associated injuries in adults. Acta Orthop Traumatol Turc. 2005;39(5):387-90.

17. Mumford J, Weistein JN, Spratt KF, et al. Thoracolumbar burst fractures. The clinical efficacy and outcome of nonoperative management. Spine. 1993; 18(8):955-70.

18. McAfee PC, Zdeblick TA. Tumors of the thoracic and lumbar spine: Surgical treatment via the anterior approach. J Spinal Disord. 1989:2:145-54.

19. Shanmugasundaram TK. The care of SCl patients in the developing nations: can we stem the rot? Paraplegia. 1988;26(1):10-1.

20. Upendra B, Mahesh B, Sharma L, et al. Correlation of outcome measures with epidemiological factors in thoracolumbar spinal trauma. Indian J Orthop. 2007:41:290-4.

21. Van Asbeck FW, Post MW, Pangalila RF. An epidemiological description of spinal cord injuries in The Netherlands in 1994. Spinal Cord. 2000;38:420-4.

22. Denis F, Armstrong GW, Searls K, et al. Acute thoracolumbar burst fractures in the absence of neurologic deficit: a comparison between operative and non-operative treatment. Clin Orthop Relat Res. 1984;189:142-9.

23. Anderson PA, Rivara FP, Maier RV, Drake C. The epidemiology of seatbeltassociated injuries. J Trauma. 1991;31:60-7.

24. Reid AB, Letts RM, Black GB. Pediatric Chance fractures: association with intra-abdominal injuries and seatbelt use. J Trauma. 1990:30:384-91.

25. Schmidt Ol, Strasser S, Kaufmann V, Strasser E, Gahr RH. Role of early minimal-invasive spine fixation in acute thoracic and lumbar spine trauma. Indian J Orthop. 2007:41(4):374-80.

26. Merom L, Raz N, Hamud C, Weisz I, Hanani A. Minimally invasive burst fracture fixation in the thoracolumbar region. Orthopedics. 2009;32:273-8. 
27. Ni WF, Huang $Y X, C h i$ YL, $X u H Z$, Lin $Y$, Wang $X Y$, et al. Percutaneous pedicle screw fixation for neurologic intact thoracolumbar burst fractures. J Spinal Disord Tech. 2010;23:530-7.

28. Pelegri C, Benchikh E, Fegoun A, Winter M, Brassart N, Bronsard N, Hovorka I, et al. Percutaneous fixation of lumbar and thoracolumbar fractures without neurological involvement: surgical technique and preliminary results. RCO. 2008;94:456-63.

29. Korovessis P, Baikousis A, Zacharatos S, et al. Combined anterior plus posterior stabilization versus posterior short-segment instrumentation and fusion for mid-lumbar (L2-L4) burst fractures. Spine. 2006;31:859-68.

30. Palmisani M, Gasbarrini A, Brodano GB, De lure F, Cappuccio M, Boriani L, et al. Minimally invasive percutaneous fixation in the treatment of thoracic and lumbar spine fractures. Eur Spine J. 2009;18:71-4.

31. Rechtine GR, Bono PL, Cahill D, Bolesta MJ, Chrin AM. Postoperative wound infection after instrumentation of thoracic and lumbar fractures. J Orthop Trauma. 2001;15:566-9.

32. Dong $\mathrm{SH}$, Chen $\mathrm{HN}$, Tian JW, et al. Effects of minimally invasive percutaneous and trans-spatium intermuscular short-segment pedicle instrumentation on thoracolumbar mono-segmental vertebral fractures without neurological compromise. Orthop Traumatol Surg Res. 2013;99(4):405-11.

33. Van der Roer N, de Lange ES, Bakker FC, et al. Management of traumatic thoracolumbar fractures: a systematic review of the literature. Eur Spine J. 2005;14:527-34.

34. Wood KB, Bohn D, Mehbod A. Anterior versus posterior treatment of stable thoracolumbar burst fractures without neurologic deficit: a prospective, randomized study. J Spinal Disord Tech. 2005;18(Suppl):15-23.

\section{Publisher's Note}

Springer Nature remains neutral with regard to jurisdictional claims in published maps and institutional affiliations.

\section{Submit your manuscript to a SpringerOpen ${ }^{\circ}$ journal and benefit from:}

- Convenient online submission

- Rigorous peer review

- Open access: articles freely available online

- High visibility within the field

- Retaining the copyright to your article

Submit your next manuscript at $\boldsymbol{\nabla}$ springeropen.com 